\title{
Identification of Cleaved Haptoglobin in the Serum of Bee Venom-Hypersensitive Patients
}

\author{
Jae-Min Ryu ${ }^{1}$, Han-Heom Na', Jin-Sung Park ${ }^{2}$, Byung-Soo Ahn ${ }^{2,3}$, Keun-Cheol Kim ${ }^{1, *}$ \\ ${ }^{1}$ Department of Biological Sciences, College of Natural Sciences, Kangwon National University, Chuncheon, Republic of Korea \\ ${ }^{2}$ Korean Pharmacopuncture Institute, Seoul, Republic of Korea \\ ${ }^{3}$ AJ Research Institute for Integrative Medicine, Seoul, Republic of Korea
}

Received December 29, 2020

Revised April 20, 2021

Accepted May 10, 2021

Correspondence to

Keun-Cheol Kim

Department of Biological Sciences,

College of Natural Sciences, Kangwon

National University, Chuncheon,

Republic of Korea

E-mail kckim@kangwon.ac.kr
Background: Bee venom has been used as a therapeutic compound for various human diseases in oriental medicine; however, it can induce anaphylaxis in hypersensitive patients during treatment. Anaphylaxis is an acute allergic reaction that occurs after allergen exposure. IgE is released from immune-related cells such as mast cells and basophils during anaphylaxis. Various inflammatory mediators are also released into the bloodstream during the acute response.

Objectives: We aimed to identify specific proteins from bee venom-hypersensitive patients.

Methods: We analyzed the blood serum of control and bee venom-hypersensitive patients using two-dimensional (2D) electrophoresis.

Results: An interesting protein spot with a molecular size of $10 \mathrm{kDa}$ was identified at an isoelectric point (p.I.) of 5.5. Spots detected both before and after sweet bee venom therapy were not proteins induced by sweet bee venom. The $10 \mathrm{kDa}$ protein was identified as the cleaved form of haptoglobin through liquid chromatography-tandem mass spectrometry (LC-MS/MS) analysis. Statistical analysis indicated that the presence of the spot was highly significant in the bee venom-hypersensitive group.

Conclusion: The findings suggest that cleaved haptoglobin may be a significant diagnostic protein for anaphylaxis. In addition, a high incidence of bee venom hypersensitivity may be associated with the haptoglobin genotype.

Keywords: Bee venom, Anaphylaxis, 2D electrophoresis, Haptoglobin, Hp2 genotype, Diagnostic protein

\section{INTRODUCTION}

Anaphylaxis is an acute allergic reaction caused by an allergen infiltrating the bloodstream of an individual [1]. Both classical and alternative pathways are known as typical physiological pathways of anaphylaxis [2]. Immunoglobulin E (IgE)-mediated anaphylaxis has been described as a classical pathway [3]. IgE is synthesized in response to allergens such as foods, medications, or insect venom [4]. Allergen-specific IgE specifically binds to the high-affinity IgE receptor (FceRI) on mast cells and basophils [5]. These cells may rapidly release histamine and tryptase into the bloodstream to induce an acute anaphylactic response. When an individual with $\operatorname{IgE}$ antibodies is exposed to the same allergen again, the secreted factors stimulate smooth muscle contraction or increased vascular permeability, inducing the functional dysregulation of the respiratory or cardiovascular system [6,7]. The IgGdependent pathway described in animal models represents a second, alternative pathway. Macrophages instead of mast cells, platelet-activating factor (PAF) instead of histamine, and $\operatorname{IgG}$ rather than $\operatorname{IgE}$, are involved in this alternative pathway [8].

Bee venom contains various physiologically active components including melittin, apamin, mast cell-degranulating (MCD) peptide, adolapin, phospholipase A2 (PLA2), and hyaluronidase [9]. Bee venom has been used therapeutically in Asia for the treatment of inflammatory diseases, such as rheumatoid arthritis, cataracts, spinal inflammation, degenerative arthritis, acute pyrolytic arthritis, paralysis, and spinal nerve damage [10]. Recent studies have suggested that bee venom exerts anti-inflammatory activity by reducing IgE levels, cytokine release, and NF-kB activity [11,12]. 
A reduction in NF-kB activity can alter the expression of inflammatory COX-2 and iNOS genes [13]. Bee venom has also been found to downregulate inflammatory cytokines, such as IL- $1 \beta$, IL- 6 , TNF- $\alpha$, and TGF- $\beta 1$, in a rheumatoid arthritis animal model, suggesting the medicinal effect of bee venom [14]. However, individuals who are sensitive to bee venom may experience symptoms such as vomiting, chills, abdominal cramps, and difficulty in breathing [15]. Therefore, although the therapeutic potential of bee venom has been scientifically demonstrated, life-threatening immune responses such as anaphylaxis are still an issue [16].

Two-dimensional (2D) electrophoresis/liquid chromatography-tandem mass spectrometry (LC-MS/MS) analysis is widely used to identify proteins of interest [17]. Several diagnostic marker proteins have been identified following 2D analysis in some disease models [18]. Apolipoprotein A1 precursor, calgranulin $\mathrm{B}$, and apolipoprotein $\mathrm{E}$ were identified as possible marker proteins for lung cancer, and increased gp96 protein and decreased annexin I may indicate liver cancer. Apolipoprotein A1 (M.W. $28 \mathrm{kDa}$ ) levels range from 0.9 to $2.1 \mathrm{~g} / \mathrm{L}$ in the serum of normal individuals; however, it is markedly reduced to $0.31-0.35 \mathrm{~g} / \mathrm{L}$ in the serum of patients with early ovarian cancer, suggesting that decreased apolipoprotein A1 may be a useful marker for ovarian cancer [19]. On the other hand, apolipoprotein AII with a molecular weight of $9 \mathrm{kDa}$ is present at high concentrations in the serum of prostate cancer patients [20].

Anaphylaxis is defined as a serious allergic reaction that is rapid in onset and may cause death. Bee venom also triggers an anaphylactic response in hypersensitive individuals. In this study, we analyzed human serum obtained from bee venom-hypersensitive patients using 2D/LC-MS/MS.

\section{MATERIALS AND METHODS}

\section{Human blood samples and ethics}

Blood samples were collected from volunteers who visited an oriental medical clinic located in Chuncheon, Kangwon, Republic of Korea. Blood (5 mL) was obtained from each individual using an 18-gauge syringe. The blood was centrifuged to separate the serum and kept at $-20^{\circ} \mathrm{C}$ until further analysis. This study was conducted after approval from the Institutional Review Board (IRB) of Kangwon National University (KWNUIRB-2019-05-011-022). Trichloroacetic acid (TCA) solution was added to precipitate the proteins overnight before centrifugation. Dithiothreitol ((DTT), 10\% in acetone) was added to stabilize the protein pellets. Urea lysis buffer (7 M urea, $2 \mathrm{M}$ thiourea, 4\% CHAPS, $65 \mathrm{mM}$ DTT, and 0.4\% 3-10 ampholyte) was added to the protein pellets for $2 \mathrm{D}$ analysis.

\section{Two-dimensional electrophoresis}

A tube gel (urea, 30\% acrylamide/bis-acrylamide 29:1 solution, 3-10 ampholyte, $100 \mu \mathrm{L}$ of $10 \%$ ammonium persulfate (APS), and $40 \mu \mathrm{L}$ of TEMED) was prepared for isoelectric focusing. Protein samples were loaded into the tube gel after heat denaturation and separated in the tube gel for $10 \mathrm{~h}$ at $1000 \mathrm{~V}$. The tube gel was stabilized in transfer buffer (0.5 M Tris- $\mathrm{HCl}, 10 \%$ sodium dodecyl sulfate (SDS), and bromophenol blue). Then, the tube gel was loaded onto a 15\% acrylamide gel, and SDS-polyacrylamide gel electrophoresis (SDS-PAGE) was performed to separate the proteins according to size. Electrophoresis was performed for $1 \mathrm{~h}$ at $80 \mathrm{~mA}$. Subsequently, the acrylamide gel was stained with Coomassie Brilliant Blue R-250 (in 50\% methanol and 10\% glacial acid) and destained with a solution containing 50\% methanol and $10 \%$ glacial acid.

\section{Identification of protein spots by LC-MS/MS}

Protein spots were cut off, destained with acetonitrile, and dissolved in methanol. LC-MS/MS analysis was performed at Proteomtech, Inc. (Seoul, Korea). In brief, a nano ACQUITY UPLC and LTQ-orbitrap-mass spectrometer were used for the analysis (Thermo Electron, San Jose, CA, USA). The column used was a BEH C18 $1.7 \mu \mathrm{m}, 100 \mu \mathrm{m} \times 100 \mathrm{~mm}$ column (Waters, Milford, MA, USA). Information on the oligopeptides was obtained from LS-MS/MS analysis. The oligopeptides were compared with those in the NCBIprot protein database by searching the mascot database (www. matrixscience.com).

\section{Statistical analysis}

Protein spots were captured by designating areas that were $1 \mathrm{~cm}$ wide and $2 \mathrm{~cm}$ long with ImageJ software (Wayne Rasband, Bethesda, MD, USA), and the intensity was quantified. All statistical analyses were performed with EXCEL software (Microsoft, Redmond, WA, USA). An F-test was performed to examine the variance in the population under the null hypothesis. A t-test was performed to examine the $\mathrm{t}$-distribution under the null hypothesis. $p<0.05$ was considered statistically significant.

\section{RESULTS}

\section{Blood donor medical information}

This study was conducted after approval by the Institutional Review Board (IRB) of Kangwon National University. Blood samples were collected from volunteers among patients who visited an oriental medical clinic located in Chuncheon, Kangwon. We analyzed the blood serum from eight control patients and eight bee venom-hypersensitive patients (Table 1). The primary reasons for visiting the clinic were skeletal 
musculoskeletal disorders and joint pain. The control group included two males and six females with an average age of 53 years; they had no history of allergic reactions from treatment with bee venom pharmacopuncture. In contrast, the bee venom-hypersensitive group showed noticeable allergic reactions during or after treatment with bee venom pharmacopuncture. Their allergic reactions varied and included flushing, itching, and edema. Itching involved the skin and mucous membranes. Particularly, patients P-02, P-04, and P-09 showed severe allergic reactions during

Table 1. Medical information on the control and anaphylaxis groups

\begin{tabular}{|c|c|c|c|c|}
\hline Group & ID & Age/Sex & Symptoms & Post-sBVT \\
\hline \multirow[t]{8}{*}{ Control } & C-02 & $39 M$ & Finger arthritis (-DIP PIP pain) & - \\
\hline & C-03 & $29 \mathrm{~F}$ & Cervical pain & - \\
\hline & C-04 & $57 \mathrm{~F}$ & Back pain & - \\
\hline & C-06 & $44 \mathrm{~F}$ & Back pain & - \\
\hline & C-09 & $60 \mathrm{~F}$ & Back pain & - \\
\hline & C-11 & $71 \mathrm{~F}$ & Knee pain & - \\
\hline & C-14 & $62 \mathrm{~F}$ & Finger arthritis (-DIP PIP pain) & - \\
\hline & C-16 & $42 \mathrm{~F}$ & Rump pain & - \\
\hline \multirow[t]{8}{*}{ Patient } & P-01 & $54 \mathrm{~F}$ & Knee joint pain & Flushing, itching \\
\hline & P-02 & $47 M$ & Cervical sprain & Flushing, itching \\
\hline & P-03 & $58 \mathrm{~F}$ & Back pain & Flushing, itching- \\
\hline & P-04 & $54 \mathrm{~F}$ & Back pain, knee pain & Flushing, itching \\
\hline & P-05 & $33 \mathrm{~F}$ & Stomachache & Flushing, itching \\
\hline & P-08 & $49 \mathrm{~F}$ & Wrist tendinitis & Flushing, itching, edema \\
\hline & P-09 & $62 \mathrm{~F}$ & $\begin{array}{l}\text { Asthma, cough, dyspnea } \\
\text { Bear's gall allergy }\end{array}$ & Flushing, itching, edema \\
\hline & P-10 & $70 \mathrm{~F}$ & Finger arthritis (-DIP PIP pain) & Flushing, itching, edema \\
\hline
\end{tabular}

${ }^{*}$ SBVT $=$ sweet bee venom therapy.

\section{C-02}

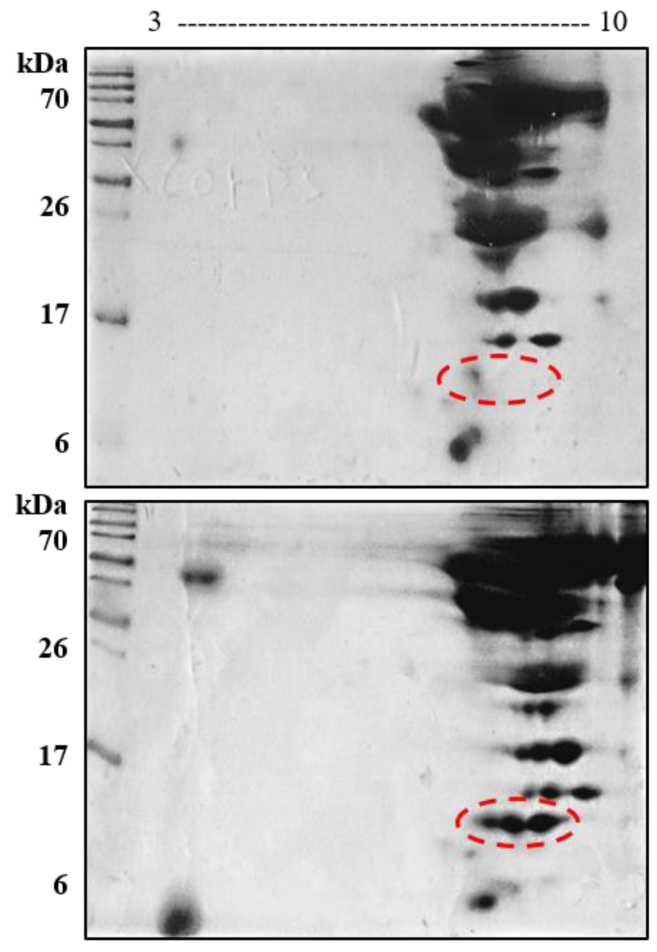

P-02

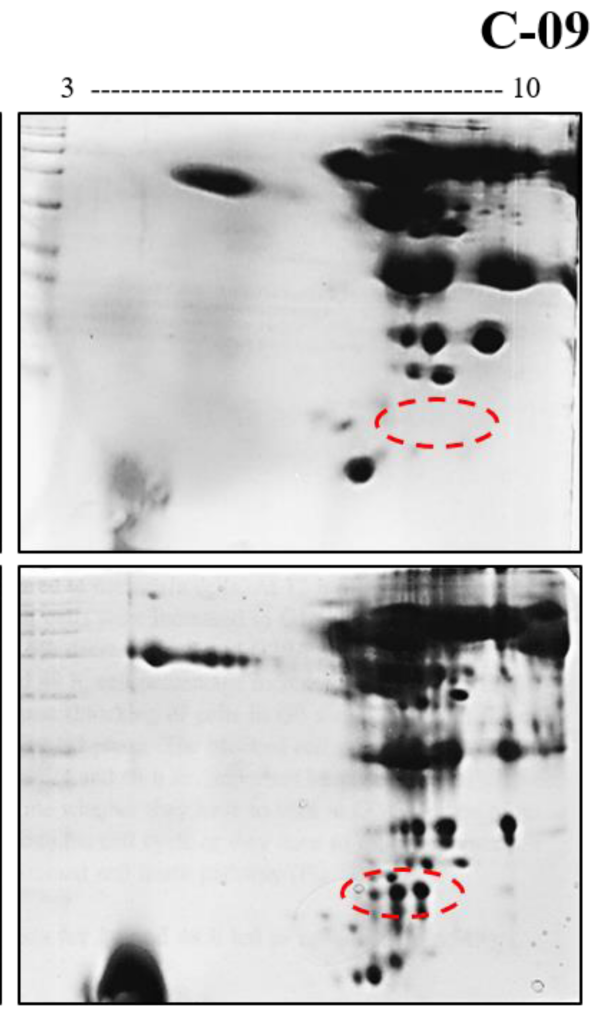

P-10
Fig. 1. Analysis of patient sera using 2D electrophoresis. Serum proteins were prepared from the control and bee venom-hypersensitive groups. A protein spot was identified in the anaphylaxis group with a p.I. of 5.5 and molecular size of $10 \mathrm{kDa}$. 
bee venom pharmacopuncture therapy. Moreover, patient P-09 had a history of asthma and showed complex allergic reactions to Fel Ursi Pharmacopunture solution (FUPS), which is used for the treatment of stress or insomnia. Antihistamines and steroid drugs were used to treat bee venom hypersensitivity for approximately three weeks. The average age of the patients in the hypersensitive group was 53 years old, which included one male and seven females.

\section{Identification of a specific protein spot in the bee venom-hypersensitive group}

Blood was collected from voluntary donors, and the serum was separated by centrifugation and subjected to 2D analysis. First, serum proteins were separated in gel tubes with an ampholyte solution ( $\mathrm{pH} 3-10)$ for 1D isoelectric focusing. Several main bands were observed in the $\mathrm{pH}$ 5-7 range. After rotating the gel tubes, 2D SDS-PAGE was performed to separate the proteins according to size. We found an interesting protein spot in the bee venom-hypersensitive group compared with the control group (Fig. 1). Molecular characterization of the protein spot showed an approximate p.I. of 5.5 and a molecular size of $10 \mathrm{kDa}$. There were one or three protein spots on the gels analyzed. We performed a $2 \mathrm{D}$ analysis of 16 serum samples obtained from the control and hypersensitive volunteers (Fig. 2). Interestingly, most spots were detected in the bee venom-hypersensitive group and were rarely observed in the control group. These results indicated that the spots were associated with bee venom sensitivity. Furthermore, we analyzed serum samples obtained from a patient before and after sweet bee venom therapy (Fig. 3). Spots were detected on the gels of both serum samples, suggesting that the spots were not proteins induced by sweet bee venom.

\begin{tabular}{|c|c|c|c|c|c|c|c|c|}
\hline & C-02 & C-03 & C-04 & C-06 & C-09 & C-11 & C-14 & C-16 \\
\hline Spot & & - & $*$ & - & & & \\
\hline Intensity & 1907.82 & 918.941 & 621.799 & 382.921 & 3066.648 & 1658.92 & 1801.012 & 1581.497 \\
\hline Spot & P-01 & P-02 & P-03 & P-04 & P-05 & P-08 & P-09 & P-10 \\
\hline Intensity & 4708.861 & 28640.397 & 10309.983 & 3740.033 & 2600.305 & 9858.033 & 25762.69 & 27449.69 \\
\hline
\end{tabular}

Fig. 2. Expression level of protein spots between the control and anaphylaxis groups. The protein spot was detected in the bee venomhypersensitive group using 2D analysis. The image was captured by ImageJ software and the intensity was quantitated.

\section{P-03}

\section{serum before sBV therapy}

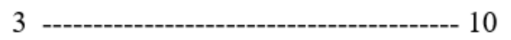

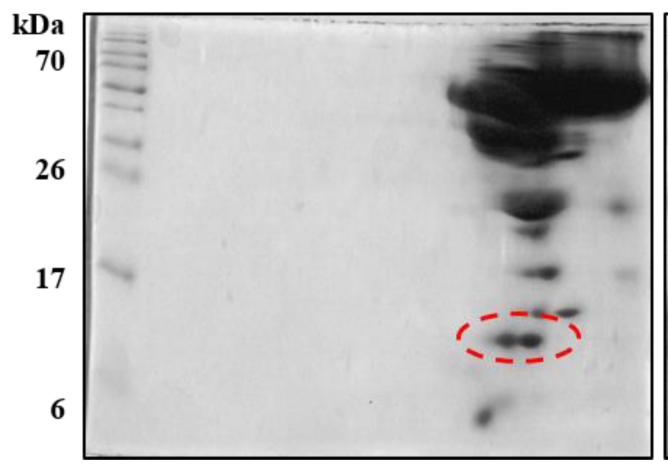

serum after sBV therapy

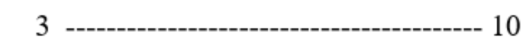

Fig. 3. 2D analysis of serum before and after sBV therapy. The protein spots were identified in both $2 \mathrm{D}$ analyses. 
A

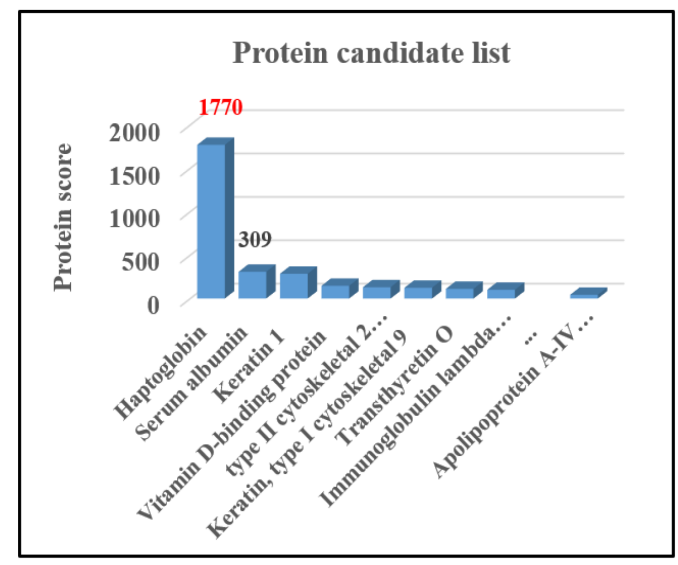

B

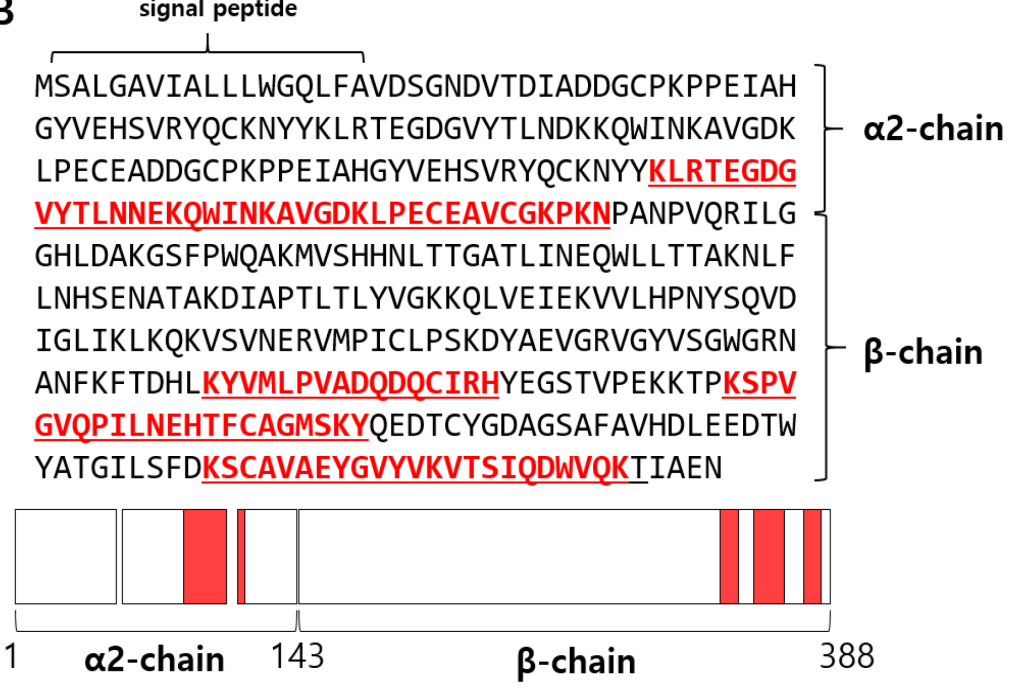

Fig. 4. Identification of the cleaved form of haptoglobin through LC-MS/MS. (A) The protein spot was trypsinized into small oligopeptides and subjected to LC-MS/MS analysis. Oligopeptide information on the spot identified it as haptoglobin based on the $\mathrm{m} / \mathrm{z}$ value. (B) The haptoglobin protein is synthetized as a single polypeptide chain containing a signal peptide of 18 amino acids and both the $\alpha 2$ and $\beta$ subunits. The red-colored oligopeptide sequence shows the exact match on the haptoglobin protein.

\section{Identification of cleaved haptoglobin through LC-MS/MS analysis}

Protein spots were cut from the acrylamide gels, trypsinized to produce oligopeptides, and subjected to LC-MS/MS analysis. The charge-to-mass $(\mathrm{m} / \mathrm{z})$ value was obtained and compared with that in the NCBIprot protein database by searching the mascot database (www.matrixscience.com). A total of 41 candidate proteins were identified including haptoglobin, which had the highest protein score (Fig. 4A). The oligopeptide sequence "RTEGDGVYTLNNEKQ" was observed with a high $\mathrm{m} / \mathrm{z}$ value. Moreover, 4-5 oligopeptides matched the amino acid sequences of haptoglobin. Haptoglobin is a protein consisting of 406 amino acids with a predicted protein size of $46 \mathrm{kDa}$ (Fig. 4B). We observed an approximately $10 \mathrm{kDa}$ protein in $2 \mathrm{D}$ analysis. The matched amino acid sequences coincided with 101 amino acids in the full haptoglobin sequence and were scattered throughout the entire haptoglobin sequence. Therefore, the protein spot may be a cleaved form of haptoglobin.

\section{Statistical analysis of the protein spot}

We performed statistical analysis to determine whether the spots observed in the bee venom-hypersensitive group were statistically significant. The protein spots were captured by designating areas that were $1 \mathrm{~cm}$ wide and $2 \mathrm{~cm}$ long with ImageJ software and quantified by measuring the intensity. The F-test was used to examine the variance in the intensity data of the protein spots, which were assumed to be heteroscedastic. We also performed t-test analysis with the heteroscedastic populations in the control and bee venom-
Table 2. Statistical analysis of the quantification of cleaved haptoglobin between the control and patient groups

\begin{tabular}{lrr} 
& Control & \multicolumn{1}{c}{ Patient } \\
\hline Average & 1492.4 & 14133.7 \\
Variance & 728497.7 & 126538642.9 \\
Count & 8 & 8 \\
F-test: $p$-value & 0.0000003 & \\
T-test: $p$-value & 0.0157207 & \\
\hline
\end{tabular}

hypersensitive groups. The $p$-value (0.015) from t-test analysis indicated that the presence of the spots was significant in the bee venom-hypersensitive group compared with the control group (Table 2).

\section{DISCUSSION}

Efforts have been made to develop disease-targeted therapeutic drugs in the biopharmaceutical market for several decades [21]. Recently, concerns regarding diagnosis in the early stage of diseases have increased [22]. Many phenotypic changes appear as cellular, biochemical, or molecular changes. Specifically, molecular changes can be detected in the blood, saliva, or sputum; thus, these changes can be quantified and can be considered as useful biomarkers [23]. The speed and accuracy of diagnostic technology should be high to identify specific marker proteins for a target disease [24].

Anaphylaxis is a serious hypersensitivity reaction with immunologic or non-immunologic mechanisms [25]. Anaphylaxis has been defined as a side effect of exposure to 
an allergen, and various mediators are released into the bloodstream in response to the allergen [26]. The mediators include factors released from mast cells or basophilic storage vesicles, as well as cytokines from immune cells [27]. Considering that many factors are secreted into the bloodstream during anaphylaxis, it is important to study serological data [28]. Previously, the concentrations of the fibrinogen alpha chain and C3 and C4-A complement proteins were reported to be altered in the sera of patients with bee venom anaphylaxis [29]. In another study, the concentration of mast cell tryptase (MCT) was increased in the serum in severe anaphylaxis [27]. Moreover, platelet activation factor (PAF), chymase, carboxypeptidase A3, dipeptidyl peptidase I (DPPI), basogranulin, and CCL2 were increased during anaphylaxis, suggesting that they may be useful biomarkers for diagnosis [30]. However, the relationship between different mediators and diagnostic markers is not fully understood [31].

In this study, we identified the cleaved form of haptoglobin as a specific protein marker in bee venom-hypersensitive patients, which may be used as a diagnostic marker protein. Haptoglobin belongs to the family of acute-phase plasma proteins and functions as a plasma detoxifier by combining with hemoglobin. The full-length haptoglobin protein is produced as a pre-pro-protein of $58 \mathrm{kDa}$, containing a signal peptide of 18 amino acids and both $\alpha$ and $\beta$ subunits. Functional haptoglobin is synthesized from a single polypeptide chain with cleavage into $\alpha$ and $\beta$ chains by c1r-like serine protease [32]. The alleles of the haptoglobin gene (Hp gene) consist of the $\mathrm{Hp} 1$ and $\mathrm{Hp} 2$ variants, and both alleles have been found in populations worldwide [33]. However, there are some reports indicating that the Hp2 allele is predominant in Asian populations, whereas the $\mathrm{Hpl}$ allele is predominant in Western populations [34]. The $\alpha 1$ chain derived from the $\mathrm{Hp} 1$ allele is a subunit of $9 \mathrm{kDa}$ covering one CCP domain, whereas the $\alpha 2$ chain derived from the $\mathrm{Hp} 2$ allele is a subunit of $14 \mathrm{kDa}$ covering two CCP domains [32]. We obtained a high number of hits on amino acids 116-154 in the $\alpha 2$ chain of haptoglobin, suggesting that the identified protein spot was the $\alpha 2$ chain of cleaved haptoglobin. However, we also obtained hits on the 297$312,325-346$, and 379-402 regions in the $\beta$ chain of fulllength haptoglobin. These results suggest that the cleaved form of haptoglobin might be a mix of partial $\alpha 2$ chains and partial $\beta$ chains. Therefore, the incidence of bee venomrelated anaphylaxis may be higher among individuals with the Hp2 allele. The expression of haptoglobin is reduced in congenital haptoglobin deficiency, hemolytic anemia, acute hepatitis, and severe liver disorders [35]. Mutations in the haptoglobin gene can cause kidney failure in diabetes, as well as Crohn's disease or Parkinson's disease [36]. The expression of haptoglobin can be induced by several growth hormones and pro-inflammatory cytokines; however, its concentration can greatly decrease during accelerated hemolysis, suggesting that haptoglobin might be a marker of the acute phase of hemolysis [37]. Although spots were detected both before and after sweet bee venom therapy, we do not know whether the cleaved form of haptoglobin was the result of exposure to bee venom or was previously present in the blood of the hypersensitive patients. Nevertheless, the spots were not proteins induced by sweet bee venom.

\section{CONCLUSIONS}

This is the first report of an abnormal cleaved form of haptoglobin as a specific protein in bee venom-hypersensitive patients, which might predict the high incidence of hypersensitivity in populations with different genotypic backgrounds. It showed an association with the occurrence of anaphylaxis during bee venom therapy. Further studies on the cleaved form of haptoglobin in populations with different genotypic backgrounds are needed to help clarify its diagnostic utility.

\section{ACKNOWLEDGEMENTS}

This work was supported by a fund from the National Research Foundation of Korea (2016R1D1A3B02006754).

\section{CONFLICT OF INTEREST}

The authors declare no conflict of interest.

\section{ORCID}

Jae-Min Ryu,

Han-Heom Na,

Jin-Sung Park,

https://orcid.org/0000-0002-2431-2362

https://orcid.org/0000-0003-3753-3129

Byung-Soo Ahn, htps://orcid.org/0000-0002-1963-3938

Keun-Cheol Kim, https://orcid.org/0000-0003-3047-0380

\section{REFERENCES}

1. Ring J, Behrendt H. Anaphylaxis and anaphylactoid reactions. Classification and pathophysiology. Clin Rev Allergy Immunol 1999;17:387-99.

2. Strait RT, Morris SC, Yang M, Qu XW, Finkelman FD. Pathways of anaphylaxis in the mouse. J Allergy Clin Immunol 2002;109: 658-68.

3. LoVerde D, Iweala OI, Eginli A, Krishnaswamy G. Anaphylaxis. Chest 2018;153:528-43.

4. Elieh Ali Komi D, Shafaghat F, Zwiener RD. Immunology of bee 
venom. Clin Rev Allergy Immunol 2018;54:386-96.

5. Stone KD, Prussin C, Metcalfe DD. IgE, mast cells, basophils, and eosinophils. J Allergy Clin Immunol 2010;125(2 Suppl 2): S73-80.

6. Pałgan K, Bartuzi Z. Platelet activating factor in allergies. Int J Immunopathol Pharmacol 2015;28:584-9.

7. Brown SG, Stone SF, Fatovich DM, Burrows SA, Holdgate A, Celenza A, et al. Anaphylaxis: clinical patterns, mediator release, and severity. J Allergy Clin Immunol 2013;132:1141-9.e5.

8. Escribese MM, Rosace D, Chivato T, Fernández TD, Corbí AL, Barber D. Alternative anaphylactic routes: the potential role of macrophages. Front Immunol 2017;8:515.

9. Wehbe R, Frangieh J, Rima M, El Obeid D, Sabatier JM, Fajloun Z. Bee venom: overview of main compounds and bioactivities for therapeutic interests. Molecules 2019;24:2997.

10. Liu CC, Hao DJ, Zhang Q, An J, Zhao JJ, Chen B, et al. Application of bee venom and its main constituent melittin for cancer treatment. Cancer Chemother Pharmacol 2016;78:111330.

11. Park HJ, Lee SH, Son DJ, Oh KW, Kim KH, Song HS, et al. Antiarthritic effect of bee venom: inhibition of inflammation mediator generation by suppression of NF-kappaB through interaction with the p50 subunit. Arthritis Rheum 2004;50: 3504-15.

12. Kim WH, An HJ, Kim JY, Gwon MG, Gu H, Jeon M, et al. Antiinflammatory effect of melittin on Porphyromonas gingivalis LPS-stimulated human keratinocytes. Molecules 2018;23:332.

13. Kim DH, Chung JH, Yoon JS, Ha YM, Bae S, Lee EK, et al. Ginsenoside Rd inhibits the expressions of iNOS and COX-2 by suppressing NF- $\kappa$ B in LPS-stimulated RAW264.7 cells and mouse liver. J Ginseng Res 2013;37:54-63.

14. El-Tedawy DM, Abd-Alhaseeb MM, Helmy MW, Ghoneim AI. Systemic bee venom exerts anti-arthritic and anti-inflammatory properties in a rat model of arthritis. Biomed Rep 2020;13:20.

15. Worm M, Edenharter G, Ruëff F, Scherer K, Pföhler C, Mahler V, et al. Symptom profile and risk factors of anaphylaxis in Central Europe. Allergy 2012;67:691-8.

16. Ebo DG, Clarke RC, Mertes PM, Platt PR, Sabato V, Sadleir PHM. Molecular mechanisms and pathophysiology of perioperative hypersensitivity and anaphylaxis: a narrative review. Br J Anaesth 2019;123:e38-49.

17. Luethy PM, Johnson JK. The use of matrix-assisted laser desorption/ionization time-of-flight mass spectrometry (MALDITOF MS) for the identification of pathogens causing sepsis. J Appl Lab Med 2019;3:675-85.

18. Gajbhiye A, Dabhi R, Taunk K, Vannuruswamy G, RoyChoudhury S, Adhav R, et al. Urinary proteome alterations in HER 2 enriched breast cancer revealed by multipronged quantitative proteomics. Proteomics 2016;16:2403-18.

19. Hariprasad G, Hariprasad R, Kumar L, Srinivasan A, Kola S, Kaushik A. Apolipoprotein A1 as a potential biomarker in the ascitic fluid for the differentiation of advanced ovarian cancers. Biomarkers 2013;18:532-41.

20. Ren L, Yi J, Li W, Zheng X, Liu J, Wang J, et al. Apolipoproteins and cancer. Cancer Med 2019;8:7032-43.

21. Liu L, Chen J, Cai X, Yao Z, Huang J. Progress in targeted therapeutic drugs for oral squamous cell carcinoma. Surg Oncol 2019;31:90-7.

22. dos Santos MCT, Barreto-Sanz MA, Correia BRS, Bell R, Widnall C, Perez LT, et al. miRNA-based signatures in cerebrospinal fluid as potential diagnostic tools for early stage Parkinson's disease. Oncotarget 2018;9:17455-65.

23. Signorelli M, Ayoglu B, Johansson C, Lochmüller H, Straub $\mathrm{V}$, Muntoni F, et al. Longitudinal serum biomarker screening identifies malate dehydrogenase 2 as candidate prognostic biomarker for Duchenne muscular dystrophy. J Cachexia Sarcopenia Muscle 2020;11:505-17.

24. Hayes B, Murphy C, Crawley A, O’Kennedy R. Developments in point-of-care diagnostic technology for cancer detection. Diagnostics (Basel) 2018;8:39.

25. Montañez MI, Mayorga C, Bogas G, Barrionuevo E, FernandezSantamaria R, Martin-Serrano A, et al. Epidemiology, mechanisms, and diagnosis of drug-induced anaphylaxis. Front Immunol 2017;8:614.

26. Castells MC. Anaphylaxis and Hypersensitivity Reactions. New York: Springer Science \& Business Media, 2010.

27. Park JP, Koo BY, Lee NW. Usefulness of mast cell tryptase analysis for postmortem diagnosis of anaphylactic shock. Korean J Leg Med 2020;44:17-23.

28. Vadas P, Gold M, Perelman B, Liss GM, Lack G, Blyth T, et al. Platelet-activating factor, PAF acetylhydrolase, and severe anaphylaxis. N Engl J Med 2008;358:28-35.

29. Matuszewska E, Matysiak J, Bręborowicz A, Olejniczak K, Kycler Z, Kokot ZJ, et al. Proteomic features characterization of Hymenoptera venom allergy. Allergy Asthma Clin Immunol 2019;15:77.

30. Beck SC, Wilding T, Buka RJ, Baretto RL, Huissoon AP, Krishna MT. Biomarkers in human anaphylaxis: a critical appraisal of current evidence and perspectives. Front Immunol 2019;10:494.

31. Peavy RD, Metcalfe DD. Understanding the mechanisms of anaphylaxis. Curr Opin Allergy Clin Immunol 2008;8:310-5.

32. di Masi A, De Simone G, Ciaccio C, D’Orso S, Coletta M, Ascenzi P. Haptoglobin: from hemoglobin scavenging to human health. Mol Aspects Med 2020;73:100851.

33. Andersen CBF, Stødkilde K, Sæderup KL, Kuhlee A, Raunser S, Graversen JH, et al. Haptoglobin. Antioxid Redox Signal 2017; 26:814-31.

34. Carter K, Worwood M. Haptoglobin: a review of the major allele frequencies worldwide and their association with diseases. Int J Lab Hematol 2007;29:92-110.

35. Mondal G, Saroha A, Bose PP, Chatterjee BP. Altered glycosylation, expression of serum haptoglobin and alpha-1- 
antitrypsin in chronic hepatitis $\mathrm{C}$, hepatitis $\mathrm{C}$ induced liver cirrhosis and hepatocellular carcinoma patients. Glycoconj J 2016;33:209-18.

36. Liu JJ, Liu S, Wong MD, Gurung RL, Lim SC. Urinary haptoglobin predicts rapid renal function decline in Asians with type 2 diabetes and early kidney disease. J Clin Endocrinol Metab
2016;101:3794-802.

37. Thielemans L, Layton DM, Shovlin CL. Low serum haptoglobin and blood films suggest intravascular hemolysis contributes to severe anemia in hereditary hemorrhagic telangiectasia. Haematologica 2019;104:e127-30. 